\title{
The impact of introducing the recent DILO card scheme on the causes for admitting patients to the Wejherowo Cancer Clinic compared to previous conditions
}

\author{
Krzysztof Adamowicz ${ }^{1}$, Marzena Wełnicka-Jaśkiewicz ${ }^{2}$
}

\begin{abstract}
Introduction. Patient waiting time for specialist consultations in oncology had ranged from a few to several weeks in 2013. This was due to there being insufficient physicians in oncology, an uneven distribution of cancer centres and that referrals were not necessarily required for attending cancer out-patient clinics. After introducing the 'Diagnosis and Treatment of Cancer' (DILO) card, reduced waiting times were intended.

Materials and methods. A retrospective study was undertaken at the hospital workplace to analyse reasons for referral in 1124 patients registering for the first time at the Cancer Clinic in Wejherowo in 2015, where those with or without DILO cards were compared. In cases of referrals for which cancer was suspected, clinical and histopathological or cytological investigations were performed. Those qualifying for radical oncological treatment were also counted in. Results. For most cases the reasons for oncological referral using DILO cards were found to be pathologies detected by imaging tests, whereas few diagnoses were made that were based on either cytological or histopathological testing, or indeed by any abnormalities observed from physical examination.

Conclusions. Based on the outcomes and experience of the authors, a practical set of guidelines has been proposed when making patient referrals to cancer out-patient clinics for consultation. Coupled with this, GPs' increased knowledge on cancer may serve to lessen the number of referrals to cancer out-patient clinics. Thus, access to oncological consultations would become facilitated.
\end{abstract}

NOWOTWORY J Oncol 2016; 66, 6: 450-456

Key words: diagnostics, general practitioner, oncology

\section{Introduction}

In Poland, General Practioner (GP) referrals are for the most part required for obtaining specialist appointments where the waiting time to the first visit varies between a few to several weeks. These times also apply when seeing oncologists, despite referrals not being needed. One of the reasons why the DILO card based system was set up was to shorten waiting times between when cancer is diagnosed to when it is treated. According to the Central Registry of Doctors, as managed by the Polish Chamber of Physicians, the numbers of doctors/medical practitioners specialising in oncology in Poland are 818 which includes 806 that are actively practicing [1]. Bearing in mind the population of Poland, of over 38.45 million, then there are 2.1 oncologists per 100,000 (i.e. 1 oncologist per 55,000). In 2013, these respectively amounted to 1.9 oncologists per 100,000 and 1 per 55,000 [2,3].

Compared to 2013, (when our first reports were published), there are still 3 oncological centres/departments in the Pomeranian region (voivodeship) where there is a great onus placed on out-patient treatment [3]. During this time, the Department of Outpatient Chemotherapy at the Medical University of Gdansk was created and the Regional (Voivodeship) Oncology Centre became joined to the 'Copernicus

${ }^{1}$ Specialist Hospital in Wejherowo, Poland

${ }^{2}$ Medical University of Gdańsk, Poland 
Medical Centre.' Smaller centres have likewise extended their range of services for cancer patients. So far, our previous 2013 study, the number of patients receiving chemotherapy has doubled at our Specialist Hospital in Wejherowo and the Department of General Surgery has been transformed into the Department of General and Oncological Surgery. All these changes are aimed to improve the availability of multi-disciplinary healthcare, that includes oncology.

At present, there are 42 oncologists in the Pomeranian region, including 36 that are in active practice [1]; in 2013, these were correspondingly 40 and 34 [3]. The European Union (EU) standard is 1 oncologist per 60,000. The Pomeranian region boasts 1 oncologist per 55,500, nevertheless access to this specialisation still appears inadequate, where possible reasons could be a lack of set guidelines for the GP in referring patients to oncologists as well as the right of patients in seeking such consultations without their GP's referral; this being pointed out in our previous publication. One of the postulates/premises of the DILO system was to deal with this problem. On the official website www.pakietonkologiczny. gov.pl one can read that patients first need to see their GP who should conduct an interview for assessing the patient's ailment(s) and, if so required, issue a referral for tests vital for diagnosing cancer; if proved to be the case, then the patient is then referred to a specialist or oncologist.

In our subjective opinion, it is exactly these types of provisions that are likely to lead to an excess of referrals to oncologists being issued without prior histopathology or cytology testing nor any additional tests being performed, thereby putting increasing burdens on the oncologist. This has become the reason we have decided to re-analyse patient referrals made to the Cancer Clinic in Wejherowo, especially taking into consideration referrals made according to the DILO scheme. Introducing the 'Oncological Package' has caused several changes, both in legal terms as well as in the competencies of GPs and outpatient care specialists (AOS) along with changing several previously obligatory practices in how patients suspected of cancer are diagnosed and treated. However, this is clearly not comparable to the situation in 2013. The Cancer Clinic in Wejherowo provides services both under the DILO card scheme as well as under the so-called 'Old System' of out-patient care. According to the DILO system, our clinic performs both initial and detailed diagnoses where furthermore, our doctors take part in multi-disciplinary consultative meetings with other departments of our hospital.

\section{Materials and methods}

The Cancer Clinic in Wejherowo operates within the F. Ceynowa Memorial Regional Hospital and is contracted by the National Health Insurance scheme to deliver oncological services/consultation and out-patient chemotherapy. It is open 5 days a week, where 3 experienced clinical on- cologists receive patients from the Pomeranian Region, together with 2 radiotherapists, 3 surgical oncologists, one pulmonary specialist and one urologist; this being 3 more doctors than in 2013. Our clinical oncologists deliver healthcare services in chemotherapy and both initial and detailed diagnoses under the DILO scheme, where they provide specialist consultation in oncology and participate in multi-disciplinary consultative meetings as well as being consultants for patients at other hospital departments. The hospital covers the town of Wejherowo and its local district as well as surrounding districts from the Pomeranian Region along with the city of Gdynia to the east of Wejherowo; in the latter case, most patients are sent to the Gdansk Oncology Centre for their treatment. In total, these regions constitute approximately 550,000 inhabitants [2].

Our study was based on the retrospective analyses of patient records such as: referrals sent by GPs and doctors of other specialisations as well as filled in DILO cards and documented records of the patient's observations and treatment course at the Specialist Hospital in Wejherowo along with those referrals resulting from consultative meetings from other centres possessing greater referentialities. The study was performed in 2016. Medical documentation from 1124 patients were analysed who had attended our Cancer Clinic from 1st January 2015 till 31st December 2015. Those suffering diseases were qualified for further analyses.

For the purposes of discussion, patients were divided into 2 groups. The first were those who came to our clinic without DILO cards, whilst the second were those with such cards obtained from their GPs or doctors with other specialisations; this also included patients who were issued DILO cards by our clinic. Patient characteristics of both these groups are presented in Table I and respectively constituted $54.4 \%$ and $45.6 \%$ of the total. The reasons behind the referrals made to our Cancer Clinic that were issued by GPs or specialist doctors under DILO scheme were divided into 4 groupings:

- Referral for diagnostics based on patient interview and/ /or abnormalities upon physical examination;

- Abnormalities from additional testing (including imaging, such as rounded shadows upon chest $X$-ray, tumours detected by ultrasonography of the abdomen, pelvis, breast, or thyroid and abnormal laboratory test results);

- Diagnosis of cancer through histopathology or cytology;

- Those patients not classified in the above groupings were qualified into a fourth group under 'others'.

The study was authorised by our hospital Director. A condition however being that complete anonymity is maintained throughout for the patient subjects when preparing databases. Statistics was performed using Microsoft Office Excel 2003 and the PQSTAT 1.4 programme. The Fisher Exact Test and Mann Whitney Test were used respectively 
Table I. Patient demographics

\begin{tabular}{lcccc}
\hline Gender & $\begin{array}{c}\text { Number of DILO } \\
\text { card-bearing patients }\end{array}$ & $\begin{array}{c}\text { Number of patients } \\
\text { without DILO cards }\end{array}$ & $\begin{array}{c}\text { Median age (range) for DILO } \\
\text { card-bearing patients }\end{array}$ & $\begin{array}{c}\text { Median age (range) for patients } \\
\text { without DILO cards }\end{array}$ \\
\hline Males & $265(23.6 \%)$ & $114(10.1 \%)$ & $67(18-90)$ & $66(39-88)$ \\
Females & $247(22.0 \%)$ & $498(44.3 \%)$ & $62(18-88)$ & $52(18-76)$ \\
Total & $512(45.6 \%)$ & $612(54.4 \%)$ & $64(18-90)$ & $57(18-88)$ \\
\hline
\end{tabular}

on categorical and continuous variables, taking significance as being $\mathrm{p} \leq 0.05$.

\section{Results \\ Patient demographics}

Women subjects constituted a majority in the study group of 1124 patients at $n=745$ (i.e. 66.3\%), with their mean age in the DILO card scheme being significantly higher than non-DILO card women; respectively 62 and 52 years $(p<0.01$ ). No such differences were observed for men. Women were more prevalent at younger ages. There were significantly more women and men aged $18-39$ years than those aged above 60 years $(\mathrm{p}<0.01)$ and significantly more men and women aged $40-59$ years than those aged above 60 years $(p<0.05)$. A decided majority of subjects $(57.3 \%)$ lived in towns (urban dwellers); $35.6 \%$ in Wejherowo itself and other towns in the vicinity at $21.7 \%$. There were $42.7 \%$ patients living in the countryside (rural areas). Most subjects attending from towns (towns and villages) lived within a radius of $50 \mathrm{~km}$ of the Wejherowo Cancer Clinic. Most study patients (54\%) were referred either from Wejherowo or its local district. Others (27\%) lived in the Puck district and 10\% in the Lebork district.

\section{GP referral data to the Clinic}

Table Il details the patient referral data (from GPs or other doctors) according to the four groupings, considering DILO and non-DILO card referral status. The largest grouping was those where cancer was diagnosed by cytology or histopathology (38.8\%) where the most common cancers found were: the lung $(36 \%)$, breast $(18 \%)$, colon $(15 \%)$, prostate (5\%) and bladder (4\%). Other cancers did not exceed $3 \%$.

\section{GP referral data to the Clinic for non-DILO card-bearing patients}

Because patients coming to the Cancer Clinic do not formally require referrals, most of them declare that they were recommended to come by their doctors. It was found that $11 \%$ of those with formal referrals had a cancer history. In the entire group, prophylactic referrals for breast cancer predominated. In the 286 women referred to the Cancer Clinic, most were aged either 40-49 years or over 60 years and who had undergone breast cancer prevention testing compared to those aged $50-69$ years $(p<0.05)$. The reasons for referring women of those ages embraced by the breast prevention programme were most frequently concerns about having cancer and being a burden to their families. From the 286 women, cancer was found in only one, however breast changes requiring treatment were found in two. In addition, abnormalities in breast imaging were detected in $6 \%$ in this women's group requiring supplementary diagnostics by means of a fine needle aspiration biopsy. The second most commonly referred group to the Cancer Clinic consisted of patients diagnosed with cancer (cytological or histopathological); the most frequent cancers were lung cancer (50\%), colon cancer (24\%), gastric cancer (10\%) and prostate and bladder cancer (5\%). In total, other cancers did not exceed $5 \%$ referrals. Of the referred subjects found with cancer, $91 \%$ were qualified for treatment of which $48 \%$ required radical therapy and $9 \%$ symptomatic treatment.

In those 80 subjects referred to the clinic because of abnormalities in imaging testing, 50\% were detected by breast ultrasonography, $10 \%$ by mammography, $18 \%$ demonstrated thyroid pathologies by ultrasound, $12 \%$ by chest $\mathrm{X}$-ray and $10 \%$ by other image tests. Only the chest X-rays

Table II. GP referral data

\begin{tabular}{|c|c|c|c|}
\hline Reasons for referral & $\begin{array}{l}\text { Number of DILO card- } \\
\text {-bearing patients (\%) }\end{array}$ & $\begin{array}{c}\text { Number of patients } \\
\text { without DILO cards (\%) }\end{array}$ & $\begin{array}{c}\text { Total patients } \\
(\%)\end{array}$ \\
\hline Prophylactic testing for breasts & $0(0 \%)$ & $286(46.7 \%)$ & $286(25.4 \%)$ \\
\hline For a diagnosis based on interview and/or physical examination & $59(11.5 \%)$ & $78(12.8 \%)$ & $137(12.2 \%)$ \\
\hline Abnormalities in additional testing & $169(33.0 \%)$ & $80(13.1 \%)$ & $249(22.2 \%)$ \\
\hline Histopathological or cytological diagnoses of cancer & $273(53.3 \%)$ & $163(26.6 \%)$ & $436(38.8 \%)$ \\
\hline Other & $11(2.2 \%)$ & $5(0.8 \%)$ & $16(1.4 \%)$ \\
\hline Total & $512(100 \%)$ & $612(100 \%)$ & $1124(100 \%)$ \\
\hline
\end{tabular}


had been previously recommended by their GPs. The other imaging tests were recommended by the out-patient specialist doctors or through private consultation. Cancer was diagnosed in 3 cases. Out of the 78 patients referred due to pathologies following physical examination or interview, 22 were diagnosed by cytology or histopathology. In all cases this was due to a physically apparent tumour of which, in 18 instances, turned out to be a metastatic lymph node or a conglomerate of metastatic lymph nodes, whilst 4 cases were primary breast tumours. None of these patients were qualified for radical treatment.

There were 5 patient referrals that came under the 'others' classification consisting of: lymphadenopathy (2), abnormal laboratory findings (2), and fatigue, malaise, and weight loss (1). In this group, none were finally diagnosed with cancer. As non-DILO card patient referrals to the Cancer Clinic did not differ to referrals made during 2010-2013, only DILO card-based referrals were further analysed by our study.

\section{GP referral data to the Clinic for DILO card-bearing patients}

All causes for referral in the DILO card-bearing patients are presented in Table III and the divisions made according to the physicians in setting up the DILO cards are shown in Table IV. DILO cards were prepared by 3 groups of physicians as follows: GPs, out-patient specialist-care doctors (other than those of the Cancer Clinic) and those of the Cancer Clinic itself. There were $89 \%$ patient subjects where cancer had been diagnosed and who were assigned for causative treatment, whilst $11 \%$ received symptomatic treatment. In the 228 patients suspected of cancer, 110 were diagnosed through cytology or histopathology; i.e. 44\% of which 31 qualified for radical treatment (31\%). Of those 169 Cancer Clinic referrals because of abnormalities found in additional tests, 80 (47.3\%) were diagnosed with cancer. In 59 DILO card-bearing subjects in whom no additional tests had been performed and who had undergone an interview by their physician, only 21 were diagnosed with cancer of which 16 had a tumour accessible to physical examination.

\section{Discussion}

Cancer is one of the common causes of morbidity in the modern world. According to WHO (World Health Organisation), the number of new cases of cancer globally will have risen from 15 million in 2000 to 15 million by 2020 [4, 5]. Within such data, the countries of South-East Asia and Central-Eastern Europe predominate [6]. The effectiveness in treating cancer in Poland is also worse than Western European countries as confirmed by the Eurocare- 3 and Eurocare-4 studies [7], where the data from 22 European countries was analysed; including Poland. These studies indicate that there still exists a gap between Western and
Eastern parts of Europe. Cancer requires specialised knowledge from doctors on differential diagnostics as well as cytology, cytogenetics, and molecular diagnostics. Individual abnormalities found upon physical examination are rarely specific enough to enable a disease-type classification. This particularly applies to any lesions found by diagnostic imaging as similar aberrations can arise through various diseases; often not oncological ones. The ability to differentiate between lesions that are potentially serious to those that are mild or inflammatory upon diagnostic imaging, should be a requirement for radiologist physicians. GPs are however required to know the correct procedures whenever abnormalities are found. Legal amendments made to healthcare services have increased the role of GPs concerning oncology, and the introduction of DILO cards was intended to reduce queuing for patients suspected of cancer, to rationalise diagnostics and treatment along with introducing rapid diagnoses and comprehensive treatment as well as decreasing cancer patient mortality and decreasing treatment costs due to earlier-stage detection of disease. In our case, those without DILO cards, radical treatment was undertaken in $48 \%$ cases in whom cancer had been diagnosed. However, in DILO patients referred by GPs, cancer was only diagnosed in $31 \%$ instances.

Within the 'oncological package', diagnostics consists of several stages. The first being when patients visit their GP, who conducts a detailed interview and assesses their ailments, making referrals for further testing that may be required; the GP is however not obliged to do the latter. Our analyses showed that there were $11.5 \%$ of patients who are referred to an oncologist without any such further testing being done. This is a considerable amount, especially as only $35 \%$ of these patients are in the end diagnosed with cancer. In addition, only 13 of these qualified for radical treatment. On the other hand, 16 of these patients had an apparently accessible tumour upon physical examination of which 12 had breast tumours. The question thus remains is as to why the GPs did not in such cases refer the patient for diagnostic breast imaging and why was this duty was passed onto the specialist physician. In this same group referred to cancer specialists, there were 12 patients who lost 2-20 kg body weight over 3 months, which to a doctor is symptom of concern. In none of these cases was a cancer diagnosis made upon making additional tests and $80 \%$ were redirected to other specialists based on endocrinological or psychiatric diagnoses that were made. Interviews that establish colonic abnormalities (presence of blood in the faeces, pencil-thin stools etc.) always lead to a colonoscopy referral. In 5 out of the 12 , colonic cancer had been diagnosed. All this leads to the conclusion that $65 \%$ of patient referrals made to a specialist oncologist based on interviews and/or physical examination did not require diagnostics by an oncologist. 
Table III. Most frequent reasons for referring DILO card-bearing patients

\begin{tabular}{|c|c|c|c|}
\hline Type of disorder & Numbers (\%) & $\begin{array}{l}\text { Number of patients finally } \\
\text { diagnosed with cancer (\%)* }\end{array}$ & $\begin{array}{l}\text { Number of patients treated } \\
\text { radically }(\%)\end{array}$ \\
\hline \multicolumn{4}{|c|}{ Referrals for diagnosis based on interview and/or physical examination abnormalities } \\
\hline Tumour found by physical examination & $18(30.5 \%)$ & $14(77.7 \%)$ & $7(50 \%)$ \\
\hline Lymphadenopathy & $17(28.8 \%)$ & $2(11.8 \%)$ & $2(100 \%)$ \\
\hline $\begin{array}{l}\text { Blood in stool, abnormal stool passage, } \\
\text { pencil-thin stools }\end{array}$ & $12(20.3 \%)$ & $5(41.7 \%)$ & $4(80 \%)$ \\
\hline Body mass loss & $11(18.6 \%)$ & $0(0 \%)$ & - \\
\hline Refractory vomiting & $1(1.7 \%)$ & $0(0 \%)$ & - \\
\hline Total & $59(100 \%)$ & $21(35.6 \%)$ & $13(62 \%)$ \\
\hline \multicolumn{4}{|c|}{ Abnormalities found by additional testing } \\
\hline Abnormalities in chest X-Ray & $61(36.1 \%)$ & $46(75.4 \%)$ & $4(8.7 \%)$ \\
\hline Abnormalities in abdominal cavity ultrasound & $38(22.5 \%)$ & $18(47.4 \%)$ & $2(11.1 \%)$ \\
\hline $\begin{array}{l}\text { Abnormalities in breast mammography or } \\
\text { ultrasound }\end{array}$ & $21(12.4 \%)$ & $11(52.4 \%)$ & $10(90.1 \%)$ \\
\hline Abnormalities in neck ultrasound & $4(2.4 \%)$ & $2(50 \%)$ & $2(100 \%)$ \\
\hline Abnormalities in circulating blood morphology & $22(13.1 \%)$ & $0(0 \%)$ & - \\
\hline Abnormalities in other tests of circulating blood & $21(12.4 \%)$ & $3(14.3 \%)$ & $0(0 \%)$ \\
\hline Other & $2(1.2 \%)$ & $0(0 \%)$ & - \\
\hline Total & $169(100 \%)$ & $80(47.3 \%)$ & $18(22.5 \%)$ \\
\hline \multicolumn{4}{|c|}{ Histopathological or cytological diagnosis of cancer } \\
\hline Lung cancer & $82(30.0 \%)$ & $82(100 \%)$ & $20(24.4 \%)$ \\
\hline Breast cancer & $80(29.3 \%)$ & $80(100 \%)$ & $64(80 \%)$ \\
\hline Colonic cancer & $48(17.6 \%)$ & $48(100 \%)$ & $31(64.6 \%)$ \\
\hline Stomach cancer & $18(6.6 \%)$ & $18(100 \%)$ & $5(27.8 \%)$ \\
\hline Prostate cancer & $15(5.5 \%)$ & $15(100 \%)$ & $13(86.7 \%)$ \\
\hline Others & 30 (11.0\%) & 30 (100\%) & 7 (23.3\%) \\
\hline Total & $273(100 \%)$ & $273(100 \%)$ & $140(51.3 \%)$ \\
\hline
\end{tabular}

${ }^{*}$ Confirmed by histopathology or cytology

The conclusions from our previous study stated that the experience of oncologists suggest that GPs rarely try to classify lesions according to diagnostic imaging, but quickly refer such patients for oncological consultation. This premise was based on the accepted working-practice hypothesis that the reasons why most referrals are made to oncologists are because of abnormalities found in additional testing but not in diagnosing cancer. The presented analyses concerning patients bearing DILO cards unfortunately confirms this. In 125 (24.6\%) cases, the reasons why DILO cards were issued were due to abnormalities in diagnostic imaging. Of these, 77 (61\%) ended up having a cancer diagnosis where the majority showed abnormalities by classic chest X-ray, which is a low-sensitivity test. Furthermore, in all cases this was just a front-back (AP) projection. The proportion of patients qualifying for radical treatment in this group was barely $8.7 \%$. In patients referred because of abnormalities found by ultrasound of the abdominal cavity, two groups can be clearly distinguished. In one are patients showing liver lesions, which by further image analysis were found to be mild, whilst the other group had liver metastases. Similar referral statistics were observed based on breast imaging and neck ultrasound. All these patients could have been diagnosed by their GPs if they had been authorised to issue referrals for CT scans or fine needle aspiration biopsy. These competencies/authorisations are at present however possessed only by Specialist Clinics and it thus seems that in the burden placed on oncologists, as herein described, a significant factor may be that other specialist AOS clinics are used too little. Even worse are the findings in those referrals made based on abnormal laboratory test results. In 43 patients bearing DILO cards for these reasons, barely 3 were diagnosed with cancer. In all cases, they had elevated PSA levels (Prostate Specific Antigen). It is also striking that in $33 \%$ patients, DILO cards were issued due to abnormalities found in additional testing; for non-DILO card bearing patients this was only $13 \%$. This observation may suggest that under the guise of having DILO cards, there is hidden the willingness for making a rapid diagnosis based on nononcological reasons. 
Table IV. Most frequent reasons for referring DILO card-bearing patients divided according to physician referrals

\begin{tabular}{|c|c|c|c|c|}
\hline Type of disorder & $\begin{array}{c}\text { Total } \\
\text { number } \\
\text { of patients }\end{array}$ & $\begin{array}{l}\text { Number of DILO card-bearing } \\
\text { patients issued by GPs }\end{array}$ & $\begin{array}{l}\text { Number of DILO card-bearing } \\
\text { patients issued by AOS }\end{array}$ & $\begin{array}{c}\text { Number of DILO card-bearing } \\
\text { patients issued by Cancer Clinic } \\
\text { physicians }\end{array}$ \\
\hline \multicolumn{5}{|c|}{ Referrals for diagnosis based on interview and/or physical examination abnormalities } \\
\hline $\begin{array}{l}\text { Tumour found by } \\
\text { physical examination }\end{array}$ & 18 & $17(94 \%)$ & $1(6 \%)$ & $0(0 \%)$ \\
\hline Lymphadenopathy & 17 & $16(94 \%)$ & $1(6 \%)$ & $0(0 \%)$ \\
\hline $\begin{array}{l}\text { Blood in stool, } \\
\text { abnormal stool } \\
\text { passage, pencil-thin } \\
\text { stools }\end{array}$ & 12 & $12(100 \%)$ & $0(0 \%)$ & $0(0 \%)$ \\
\hline Body mass loss & 11 & $11(100 \%)$ & $0(0 \%)$ & $0(0 \%)$ \\
\hline Refractory vomiting & 1 & $1(100 \%)$ & $0(0 \%)$ & $0(0 \%)$ \\
\hline Total & 59 & $57(97 \%)$ & $2(3 \%)$ & $0(0 \%)$ \\
\hline \multicolumn{5}{|c|}{ Abnormalities found by additional testing } \\
\hline $\begin{array}{l}\text { Abnormalities in chest } \\
\text { X-Ray }\end{array}$ & 61 & $48(79 \%)$ & $4(7 \%)$ & $9(15 \%)$ \\
\hline $\begin{array}{l}\text { Abnormalities in } \\
\text { abdominal cavity } \\
\text { ultrasound }\end{array}$ & 38 & $20(53 \%)$ & $9(24 \%)$ & $9(24 \%)$ \\
\hline $\begin{array}{l}\text { Abnormalities in } \\
\text { breast mammography } \\
\text { or ultrasound }\end{array}$ & 21 & $1(5 \%)$ & $1(5 \%)$ & $19(90 \%)$ \\
\hline $\begin{array}{l}\text { Abnormalities in neck } \\
\text { ultrasound }\end{array}$ & 4 & $3(75 \%)$ & $1(25 \%)$ & $0(0 \%)$ \\
\hline $\begin{array}{l}\text { Abnormalities in } \\
\text { circulating blood } \\
\text { morphology }\end{array}$ & 22 & $22(0 \%)$ & $0(0 \%)$ & $0(0 \%)$ \\
\hline $\begin{array}{l}\text { Abnormalities in other } \\
\text { tests of circulating } \\
\text { blood }\end{array}$ & 21 & $19(14.3 \%)$ & $2(0 \%)$ & $0(0 \%)$ \\
\hline Others & 2 & $2(100 \%)$ & $0(0 \%)$ & $0(0 \%)$ \\
\hline Total & 169 & $115(68 \%)$ & $17(10 \%)$ & $37(22 \%)$ \\
\hline \multicolumn{5}{|c|}{ Histopathological or cytological diagnosis of cancer } \\
\hline Lung cancer & 82 & $0(0 \%)$ & $20(24 \%)$ & $62(76 \%)$ \\
\hline Breast cancer & 80 & $0(0 \%)$ & $0(0 \%)$ & $80(100 \%)$ \\
\hline Colonic cancer & 48 & $1(2 \%)$ & $3(6 \%)$ & $44(92 \%)$ \\
\hline Stomach cancer & 18 & $0(0 \%)$ & $5(28 \%)$ & $13(72 \%)$ \\
\hline Prostate cancer & 15 & $0(0 \%)$ & $8(53 \%)$ & $7(47 \%)$ \\
\hline Others & 30 & $1(3 \%)$ & $7(23 \%)$ & $22(73 \%)$ \\
\hline Total & 273 & $2(1 \%)$ & $43(16 \%)$ & $228(84 \%)$ \\
\hline \multicolumn{5}{|c|}{ All DILO cards } \\
\hline All w/w & 511 & $174(34 \%)$ & $62(12 \%)$ & $265(53 \%)$ \\
\hline $\begin{array}{l}\text { Proportion of DILO } \\
\text { cards verified as 'cancer' }\end{array}$ & $72 \%$ & $48 \%$ & $90 \%$ & $88 \%$ \\
\hline
\end{tabular}

A consequence of taking such actions in this way, is a significantly increased number of patients that are required to have oncological consultations, which prolongs waiting times for their first specialist visit and impedes those seriously ill from being admitted that require rapid interventions. At this point the $\mathrm{n}=236$ group of DILO card-bearing patients $(53.3 \%)$ with cancer diagnosed by cytology and histopathology should be mentioned insomuch that $88 \%$ had their cards issued by an oncologist physician. In the author's opinion, it is just this group that has gained most advantage from rapid diagnostics and the option for establishing a treatment plan prepared by a multi-disciplinary consultation. This is particularly the case if one considers that a physician from the Cancer Clinic can issue DILO cards 
whenever cancer was returned or progression is suspected and in this whole group, $51 \%$ were qualified for radical treatment.

The presented study entirely confirms the accepted premise about burdening oncologist physicians with the diagnosing of non-cancer patients. A decided majority of patients referred to the Cancer Clinic possessing DILO cards were those who were not diagnosed with cancer. Our analyses demonstrated the smallest numbers of cancer diagnoses in DILO card bearing patients in those without having any additional testing done. Furthermore, our results clearly show that DILO card bearing patients did not qualify more often to radical treatment compared to those without.

Data analysis of physicians issuing DILO cards clearly show that only a very few cards were issued by medical specialist compared to those from the Cancer Clinic. Referrals for diagnosis based on interviews and/or abnormalities found after physical examination were given only by GPs, which is in keeping with the postulates of the 'oncology package' according to which medical specialist can issue DILO cards at the stage at which cancer is confirmed when aimed at undertaking a detailed/in depth diagnosis. In such cases Cancer Clinic physicians very often decide to issue DILO cards We are unable to say whether the small numbers of DILO cards issued by medical specialist other than the Cancer Clinic is due to local conditions or those imposed by the system. We also don't know how many of the DILO cards issued by GPs were rejected by medical specialist other than the ones from the Cancer Clinic. Nevertheless, it seems to us that the postulates of the 'oncology package' do not sufficiently detail this issue and, because of this, a stream of patients that require specialist diagnosis become redirected to Cancer Clinics. A collation of these findings by the funding body (National Health Insurance) would be interesting.

The study is the first of its kind, (after the introduction of DILO cards), for assessing the structure of admissions to regional Cancer Clinics in areas where there are no other oncology centres in operation and where there are no private oncology services admitting patients. In our opinion, a part of the patients could have been kept under observation for longer by the GPs, which would thereby have excluded the ones with transitory and reactive lesions. Some of the patients, particularly those with mild lesions to the breast or with equivocal lesions detected by imaging of the lungs or liver, could have been left under observation for longer if GPs had the means for referring fine needle aspiration biopsies or CT scans that frequently resolve-away any oncological concerns/worries. This especially applies to patients with lesions detected by classical X-Ray of the chest which appears as a weak shadow or by abnormalities in the liver or adrenal gland as revealed by ultrasound of the abdominal cavity (corresponding to hepatic angiomas and adrenal ademomas). Thus, significant reductions would have been made both in the number of patients waiting for specialist consultations and in unnecessary diagnoses within the framework of having a rapid oncological pathway. Nonetheless, patients suffering from proliferative diseases require an unreservedly fast consultation. Similarly, urgent treatment is necessary for patients with life-threatening disorders. Estimating healthcare needs in oncology remains an open question for discussion, however there is no interest in this issue and the reasons for this are ambiguous. The presented situation leads to an uneven access to oncological healthcare throughout the whole of Poland.

\section{Conflict of interest: none declared}

Krzysztof Adamowicz, MD, PhD

Specialist Hospital in Wejherowo

Jagalskiego 10

84-200 Wejherowo, Poland

e-mail:krzys.adamowicz@gmail.com

Received: 11 Jul 2016

Accepted: 24 Oct 2016

\section{References}

1. Naczelna Izba Lekarska; http://www.nil.org.pl/.

2. Nowak L, Stańczyk J, Znajewska A. Ludność. Stan i struktura w przekroju terytorialnym (Stan w dniu 30 VI 2013 r.). Warszawa: Główny Urząd Statystyczny, 2013. Available at: www.stat.gov.pl.

3. Adamowicz K, Wełnicka-Jaśkiewicz M. Analiza przyczyn zgłaszania się pacjentów do Poradni Onkologicznej w Wejherowie. Onkol Prakt Klin 2014; 10: 231-238

4. Ferlay J, Bray P, Pisani P et al. GLOBOCAN 2002: Cancer incidence, mortality and prevalence worldwide. IARC CancerBase No.5, Version 2.0. Lyon: IARC Press, 2004.

5. Stewart BW, Kleihues P. World Cancer Report WHO. Lyon: IARC Press, 2003.

6. Cooper RA. The medical oncology workforce: An economic and demographic assessment of the demand for medical oncologists and hematologist-oncologists to serve the adult population to the year 2020. Available at: www.slideshare.net/terrybear11/the-medical-oncology-workforce.

7. Berrino F, De Angelis R, Sant M et al., EUROCAREWorking Group. Survival for eight major cancers and all cancers combined for European adults diagnosed in 1995-99: results of the EUROCARE-4 study. Lancet Oncol 2007; 8: 773-783. 